\title{
PORNOGRAFIA E SEXUALIDADE: UMA DENÚNCIA DA CONDIÇÃO FEMININA
}

\author{
Raisa Duarte da Silva Ribeiro* \\ Marcela Siqueira Miguens*
}

RESUMO: a pornografia vem sendo alvo de discussão e fortes críticas pelas correntes feministas, em especial no cenário estadunidense. O presente trabalho possui o escopo de analisar as críticas realizadas pelo movimento feminista anti-pornografia, que enfatiza os efeitos negativos causados pela produção e pelo consumo dos materiais pornográficos. Para isso, em um primeiro momento, traça-se a distinção entre pornografia e obscenidade, com base na jurisprudência da Suprema Corte norte-americana, com o objetivo de observar os valores que estão em jogo e os direitos violados por cada um desses materiais. Em segundo lugar, são trazidas as principais críticas do feminismo de segunda onda à pornografia, que envolve diversas formas de violência contra a mulher. Em terceiro momento, serão investigados os efeitos causados pela pornografia na construção da sexualidade feminina.

PALAVRAS-CHAVE: Direitos Fundamentais; Direitos Humanos das Mulheres; violência de gênero; pornografia; sexualidade

\section{PORNOGRAPHY AND SEXUALITY: COMPLIANT OF FEMALE CONDITION}

ABSTRACT: The pornography has been discussed and criticized by the feminist groups, specially in the United States. This work intends to analyze the main criticisms of the antipornography movement, specially about the effects of production and consume of pornography in violence against women and the gender unequality. For this, first, the diferences and the similities between pornography and obscenity in the United States judicial law was analyzed. Second, the anti-pornography feminist moviment main arguments against the pornography was analyzed, notably the achievement of diferentes forms of gender violence. At least, some of the reflexes of pornography in construction of women's sexuality was observed.

KEY-WORDS: Fundamentals rights; woman's human rights; gender violence; pornography; sexuality.

\footnotetext{
* Mestre em Direito Constitucional pela Universidade Federal Fluminense (2016), pós-graduada em Direitos Humanos pelo Instituto Ius Gentium Conimbrigae/Centro de Direitos Humanos da Universidade de Coimbra (2012), pós-graduada em Direito Público e em Advocacia Pública pela Universidade Cândido Mendes (2014 e 2016). Professora de Direitos Humanos e Direitos Fundamentais da Universidade Veiga de Almeida e Centro Universitário Carioca. Pesquisadora do Núcleo Interamericano de Direitos Humanos da Faculdade Nacional de Direito da Universidade Federal do Rio de Janeiro. Advogada. E-mail: raisaribeiro@hotmail.com; endereço postal: Rua Fagundes Varela 473/1003, Icaraí-Niterói, RJ.

* Doutora e Mestre em Direito Penal pela Universidade do Estado do Rio de Janeiro. Professora Adjunta de Direito Penal e de Processo Penal da Universidade Federal Rural do Rio de Janeiro e da Universidade Veiga de Almeida. Advogada. E-mail: marcelasmiguens@gmail.com; endereço: Rua Jorge Rudge, 147, casa 25, Vila Isabel, Rio de Janeiro-RJ, CEP 20550-220
} 


\section{Raisa Duarte da Silva Ribeiro \& Marcela Siqueira Miguens}

\section{INTRODUÇÃO}

O presente trabalho possui por escopo observar os reflexos causados pela pornografia tradicional à condição da mulher dentro da sociedade bem como os seus efeitos e correlações com a construção da sexualidade feminina. Neste intuito, serão analisadas as críticas realizadas pela corrente feminista anti-pornografia e os estudos de alguns autores estruturalistas e construtivistas sociais acerca da sexualidade.

Alguns estudiosos e sociólogos estruturalistas e construtivistas sociais já enunciaram que a sexualidade não pode ser vista como um dado isolado da natureza, mas como algo construído social e culturalmente dentro do contexto em que se insere. Com base nos ensinamentos originários de Michel Foucault ${ }^{1}$, Pierre Bourdieu ${ }^{2}$ e, posteriormente, de Michel Bozon $^{3}$, a sexualidade passou a ser analisada como um dado socialmente construído, indissociável da sociedade em que se insere.

Por ser um fenômeno construído social e culturalmente, a sexualidade é influenciada, remodelada e aperfeiçoada pelas práticas sociais existentes. Neste contexto, a pornografia pode trazer grandes influxos na sua construção, em razão de refletir e reforçar as realidades existentes. Não se pode deixar de esquecer também a necessidade de se observar a construção da sexualidade e da pornografia dentro do contexto cultural em que elas estão inseridas ${ }^{4}$.

A partir da década de oitenta, algumas vozes se intensificaram no sentido de criticar a pornografia, em razão desta gerar violência contra a mulher, sendo vista como uma prática política central no controle econômico e cultural dos homens sobre as mulheres.

\footnotetext{
${ }^{11}$ Michel Foucault foi um filosofo francês e teórico social associado ao pós-estruturalismo e ao pós-modernismo, embora refutasse estas identificações e se classificasse como um pensador da história crítica da modernidade. Através de seu estudo sobre a história da sexualidade, realizado em três tomos, Michel Foucault se tornou referência no estudo da sexualidade, analisando a sua evolução no mundo ocidental.

${ }^{2}$ Pierre Bordieu consiste em um escritor francês referência nos estudos na antropologia e na sociologia, realizando contribuições importantes no campo da sexualidade. Filiado ao construtivismo estruturalista, também conhecido como estruturalismo construtivista, Pierre Bordieu acreditava que existiam estruturas objetivas no mundo social que podiam coagir a ação dos indivíduos, sendo que estas estruturas são construídas também pelo corpo social.

${ }^{3}$ Michel Bozon é um antropologo e sociológo francês que possui estudos renomados sobre a sexualidade no âmbito das ciências sociais, filiado ao construtivismo social.

${ }^{4}$ Neste sentido, as análises realizadas neste trabalho não podem ser transplantadas para todo e qualquer país e continente, em razão das limitações provenientes do relativismo cultural: o que pode ser visto como obsceno ou pornográfico em determinada cultura, pode não ser considerado da mesma forma em outra.
} 
Dentre estas vozes, destacam-se as ativistas da segunda onda do feminismo ${ }^{5}$ Diana Russell $^{6}$, Catharine Mackinnon ${ }^{7}$, Andrea Dworkin ${ }^{8}$ e Gail Dines ${ }^{9}$. Essas pesquisadoras fazem parte do movimento feminista anti-pornografia e ressaltam que a pornografia é um importante fator de exteriorização do ponto de vista masculino sobre a sexualidade, que transforma a realidade, gerando o silenciamento da mulher e estimulam práticas ilícitas de violência de gênero.

No cenário estadunidense, o debate sobre a pornografia encontra-se afiado, permeando entre grupos filosóficos e políticos que são contrários a pornografia, entre grupos que são contra a censura da pornografia mas que são críticos da pornografia misógina e também entre grupos que são pró-pornografia que valorizam o discurso como uma forma de subverter as tradicionais construções de gênero e de empoderar a sexualidade feminina.

Parcela significativa destes debates sobre a pornografia está centrada nos seus efeitos, em especial no questionamento acerca da pornografia erotizar a violência e a submissão feminina, aumentar os índices de violência contra a mulher, crianças e outros grupos vulneráveis, estimular o assédio sexual e racial assim como outras práticas misóginas.

Tendo em vista os inúmeros debates existentes sobre a pornografia, o presente trabalho pretende enfocar nas críticas realizadas pela corrente feminista anti-pornografia

\footnotetext{
${ }^{5} \mathrm{O}$ movimento feminista é classificado em três ondas. Em breve síntese, a primeira onda do feminismo, também intitulada de feminismo liberal, considera que homens e mulheres são iguais, equivalentes em seus direitos e não devem sofrer distinções entre si; o direito ao sufrágio feminino e o direito ao trabalho foram as grandes pautas desta causa. A segunda onda do feminismo, também intitulado de feminismo radical, observa a existência de diferenças entre os gêneros, pleiteando por um novo sentido do termo igualdade; esta onda, além de lutar pela valorização do trabalho da mulher, luta ativamente contra a violência em face da mulher e o direito ao prazer feminino. A terceira onda do feminismo, também conhecida como pós-feminismo, discute alguns dos paradigmas estabelecidos pelas duas primeiras ondas, mostrando que o discurso universal é excludente e trazendo a micropolítica para a discussão pública. (OLIVEIRA, 2014)

${ }^{6}$ Diana E. H Russell é uma feminista radical africana, que atua ativamente nos Estados-Unidos na luta contra a violência sexual contra mulheres e meninas, possuindo livros e artigos publicados sobre estupro, feminicídio, incesto, misoginia e pornografia.

${ }^{7}$ Catharine Alice Mackinnon é uma feminista radical americana, professora, advogada e ativista. O pensamento de Mackinnon se pauta em alguns temas centrais, em especial na crítica ao assédio sexual, a pornografia, a prostituição e ao tráfico internacional de mulheres.

${ }^{8}$ Andrea Rita Dworkin foi uma escritora feminista norte-americana, que focou a sua carreira e atuação política contra a grande indústria pornográfica, realizando críticas à pornografia em razão desta causar violência em face da mulher. Após escapar de um casamento violento, tornou-se feminista radical, ganhando destaque internacional por ser uma das grandes oradoras do movimento feminista anti-pornografia. Junto com Catharine Mackinnon, Andrea Dworkin utilizou o seu conhecimento teórico para a aplicação prática, redigindo a lei de direitos civis de Minneapolis e de Indianápolis, que, em suma, visavam permitir que as mulheres que sofressem violência em razão da pornografica conseguissem tutela judicial e reparação de danos.

${ }^{9}$ Gail Dines é uma feminista anti-pornografia inglesa, além de professora e escritora com atuação profissional nos Estados-Unidos. Dines é uma das fundadoras do movimento Stop Porn Culture e co-fundadora do Movimento Nacional Feminista Anti-Pornografia.
} 


\section{Raisa Duarte da Silva Ribeiro \& Marcela Siqueira Miguens}

existente no cenário estadunidense. Cabe ressaltar que as críticas realizadas por esta vertente contrária a pornografia não são pautadas em agendas moralistas ou conservadoras, mas sim nos efeitos reais causados pela pornografia, em especial na promoção da violência contra a mulher.

Neste intuito, o presente trabalho se divide em três partes. Em um primeiro momento, será realizada a diferenciação entre a pornografia e a obscenidade, à luz da jurisprudência estadunidense e, mais especificamente, dos ensinamentos críticos de Catharine A. Mackinnon e Andrea Dworkin. Em um segundo momento, será explicitada as principais críticas realizadas à pornografia pela segunda onda do feminismo. Em um terceiro momento, são observados os possíveis efeitos que a pornografia gera na construção cultural da sexualidade e da condição feminina na sociedade.

\section{PORNOGRAFIA E OBSCENIDADE}

Os embates realizados no constitucionalismo estadunidense sobre a pornografia não realizam um recorte da espécie de pornografia analisada. As críticas realizadas pela corrente feminista anti-pornografia não são delimitadas em uma espécie específica de pornografia.

Assim, não há a delimitação da análise entre pornografia heterossexual, lésbica, gay, bissexual ou travesti. Não se delimita a análise apenas à indústria pornográfica ${ }^{10}$, mas também pode englobar o pornô amador. Não se insere a discussão apenas na pornografia soft core, onde o material pornográfico apresenta imagens de nudez e cenas que apenas sugerem a relação sexual ou em hard core, onde há a realização de relações sexuais com penetração, sendo também alvo de análise a pornografia BDSM (bondage e sadomasoquista), que envolve práticas sadomasoquistas e violentas, a pornografia snuff, onde as pessoas praticam relações sexuais e encenam assassinato, a pornografia infantil, que envolve atos sexuais com crianças e a pornografia gonzo, onde o diretor é o próprio operador de câmara e muitas vezes atua com os atores, dentre outras espécies.

Passada esta explicação, cabe observar, em um primeiro momento, quais são as diferenças e correlações existentes entre a pornografia e a obscenidade, para que então se possa adentrar na análise das críticas dirigidas à pornografia. Nos Estados-Unidos a pornografia é permitida e tutelada, sendo apenas restringida quando envolver conteúdo obsceno, através dos critérios estabelecidos pela Suprema Corte norte-americana.

\footnotetext{
${ }^{10}$ Inicialmente, o movimento feminista anti-pornografia se dirigia a grande indústria pornográfica. Nos Estados Unidos, estas críticas eram dirigidas em especial as Revistas PentHouse, Hustler e Playboy. Posteriormente, com o avanço da tecnologia e o acesso aos filmes pornográficos, o movimento feminista anti-pornografia passou a englobar também o pornô amador.
} 
As críticas da corrente feminista anti-pornografia se dirigem a outros fatores causados pela pornografia que não a obscenidade, sendo necessário, portanto, observar os pontos de distinção e tangenciamento destes dois conceitos, para que se possa entender de forma mais lúcida os discursos enunciados.

A pornografia deriva das palavras gregas porne e graphein, que significam, respectivamente, “prostituta” e “escrita”. Assim, etimologicamente, a pornografia pode ser definida como escritos sobre a prostituição; sendo vista de forma mais específica como a produção de materiais pornográficos que retratem mulheres como prostitutas vis, devendo esse conceito ser compreendido dentro do universo da dominação masculina - afinal, prostitutas existem para servir à sexualidade masculina (DWORKIN, 1989, p. 200).

O conceito de pornografia, no entanto, não é um conceito universal. Para Diana E. H Russel, a dificuldade de se definir a pornografia é uma estratégia empregada pelos oponentes à corrente anti-pornografia para defender que não havendo consenso sobre o significado da pornografia não se pode examinar os seus efeitos, ridicularizando assim os argumentos contrários a esta prática política opressora (1993, p. 07).

De forma geral, pornografia tradicional ${ }^{11}$ pode ser definida como a exibição gráfica de materiais sexuais, nos quais a sexualidade feminina seja mostrada de forma subalterna e haja a degradação de mulheres ${ }^{12}$, deflagrada através de comportamentos agressivos, abusivos e degradantes, em contexto de dominação masculina, de maneira que se pareça endossar, encorajar ou normalizar a violência de gênero (RIBEIRO, 2017, p.48-49).

Nos Estados-Unidos a pornografia é amplamente tutelada pela liberdade de expressão, através da cláusula aberta da Primeira Emenda do Bill Of Rights. Todavia, a Suprema Corte

\footnotetext{
${ }^{11}$ Destaca-se que o tipo de pornografia que ora se identifica como objeto de estudo é a chamada pornografia tradicional, ou seja, aquela feita sob os standards clássicos da sexualidade.

12 De acordo com Catharine Mackinnon e Andrea Dworkin (1989, p. 34), “a pornografia é a subordinação sexual gráfica explícita da mulher através de imagens e/ou palavras que também podem incluir: (i) mulheres sendo apresentadas como objetos sexuais desumanizados, coisas ou bens de consumo, (ii) mulheres sendo apresentadas como objetos sexuais que gostam da dor ou da humilhação, (iii) mulheres sendo apresentadas como objetos sexuais que experimentam prazer sexual enquanto são estupradas; (iv) mulheres sendo apresentadas como objetos sexuais sendo enforcadas, cortadas, mutiladas, machucadas ou fisicamente cortadas; (v) mulheres sendo apresentadas em posturas ou posições de submissão sexual, servilidade ou exposição; (vi) exibição e redução da mulher as partes dos seus corpos, incluindo não apenas vaginas, seios ou nádegas; (vii) mulheres apresentadas como prostitutas por natureza; (viii) mulheres sendo penetradas por objetos ou animais; (ix) mulheres sendo apresentadas em cenários de degradação, dano, tortura, sendo exibidas como imundas ou inferiores, sangrando, machucadas ou mutiladas em condições sexuais” (tradução livre; DWORKIN, MACKINNON, 1989, p. 34). Além disto, para as autoras, o uso de homens, crianças ou transexuais na posição das mulheres também é considerado pornografia
} 
norte-americana já se pronunciou no leading case Miller v. California, 413 U.S 15 (1973), no sentido de trazer critérios para a restrição da pornografia que seja considerada obscena.

O mencionado leading case foi uma evolução dos julgados anteriores que envolviam a obscenidade -Roth vs. United States (1957) e Fanny Hill vs. Massachusetts (1966) - e determinou que apenas os materiais pornográficos considerados obscenos poderiam ser restringidos, sem afrontar a cláusula aberta da Primeira Emenda, que consagra a liberdade de expressão (RIBEIRO, COSTA, 2017).

Neste julgado fixou-se os parâmetros do "teste da obscenidade”, ou seja, que um material pornográfico seja considerado obsceno, ele deve preencher três requisitos. Em primeiro lugar, deve apelar para interesses lascivos. Em segundo lugar, deve mostrar ou descrever conduta sexual de um modo patentemente ofensivo e inaceitável. E em terceiro lugar, ao ser considerado como um todo, o material não deve conter nenhum valor literário, artístico, político ou científico (RIBEIRO, COSTA, 2017).

A palavra obsceno deriva do latim obscenu, que se refere a algo indecente, sem pudor, que ofende os sentidos. A obscenidade seria algo impuro, desonesto, que fere o pudor. De acordo com o Novo Dicionário da Língua Portuguesa (1986, p. 1210), obscenidade significa “1. Qualidade de obsceno. 2. Palavra, gesto, ato, imagem obscenos” e obsceno “Adj. 1. Que fere o pudor; impuro, desonesto. 2. Diz-se de quem profere ou escreve obscenidades”.

A respeito da obscenidade e da pornografia, Catharine A. Mackinnon faz algumas distinções. Em sua visão, a obscenidade refere-se a moral, ao bom e ao ruim, a virtude e ao defeito, enquanto que a pornografia se refere uma prática política de relações de poder, onde há a submissão da mulher. A obscenidade é abstrata, não gera maiores efeitos no mundo real; já a pornografia é concreta, (re)produzindo a realidade. A obscenidade seria vista como uma ideia acerca da moralidade sexual, enquanto a pornografia é ação, na medida em que interfere na construção da realidade social, representando uma prática política pautada no primado da dominação masculina e da inferioridade da mulher, o que perpetua a violência de gênero. A obscenidade não pode causar nada além de um provável pequeno dano, já a pornografia contribui e causa atitudes e comportamentos de violência e de discriminação, que define o tratamento e o status de metade da população (MACKINNON, 1989, p. 196).

A utilização do critério da obscenidade realizada pela Suprema Corte NorteAmericana define e controla quando o sexo pode ser publicamente mostrado, não se considerando a pornografia um problema que afeta a igualdade de gênero (MACKINNON, 1989, p. 196). 
Além disto, a obscenidade é um conceito jurídico indeterminado e vem sendo observada através de parâmetros também indefinidos, sendo a sua aplicação prática difícil de ocorrer pela Suprema Corte.

A pornografia precisa ser definida de forma distinta da obscenidade, em razão da diferença de seus impactos na realidade social. Todavia, ainda paira muita confusão com relação a esses dois conceitos. O próprio Dicionário da Língua Portuguesa (1986, p. 1367), ao trazer o conceito de pornografia traz uma singela confusão desta com a obscenidade: “1. Tratado acerca da prostituição. 2. Figura(s), fotografia(s), filme(s), espetáculo(s), obra literária ou de arte, etc., relativos a, ou que tratam de coisas ou assuntos obscenos ou licenciosos, capazes de motivar ou explorar o lado sexual do indivíduo. 3. Devassidão, libidinagem”.

Pelo exposto, a pornografia se difere da obscenidade, sendo que no ordenamento estadunidense apenas o material pornográfico classificado como obsceno é passível de ser restringido. Ambos os conceitos podem ser vistos como indeterminados, em razão da dificuldade teórica de sua categorização, mas isto não inviabiliza a sua caracterização prática. No entanto, é notório que a pornografia e a obscenidade são conceitos tangentes, mas autônomos. Há uma linha tênue que divide o que seria obscenidade e o que seria pornografia. Além disto, os conceitos indeterminados fixados pelo ordenamento jurídico estadunidense para definir o que seja obscenidade padece de aplicação prática e não é consistente para proteger e tutelar as mulheres que se encontram em situação de violência por causa da pornografia.

\section{PRINCIPAIS CRÍTICAS DO FEMINISMO ANTI-PORNOGRAFIA}

As feministas anti-pornografia pautam seus argumentos em diversas questões centrais, os quais se tentará sintetizar neste momento. Um relevante ponto central de crítica consiste no fato da pornografia tratar as mulheres - ou outros grupos vulneráveis, como crianças e transexuais - como objetos sexuais desumanizados. Sobre este tema, diversas discussões podem ser desmembradas.

Neste contexto, cabe salientar que, de acordo com o filósofo moral Bernand Williams, os seres humanos possuem dois valores ordinários fundamentais: auto-respeito e reação a dor, sendo que estas duas qualidades são negadas a mulher pela pornografia (WILLIAMS, apud MACKINNON, 1989, p. 210). As mulheres na pornografia se excitam enquanto são degradadas e sentem prazer na dor. Na pornografia, as mulheres pedem por isso, imploram por isso e conseguem isso. A negação destes valores permite a erotização do seu lado negativo; e, neste

Revista Brasileira de Direitos e Garantias Fundamentais | e-ISSN: 2526-0111 | Salvador | v. 4 | n. 1 | p. 148 - 168 | Jan/Jun. 
intuito, a depreciação e a tortura passam a serem vistos como uma qualidade do sexo (MACKINNON, 1989, p. 210-211).

Na pornografia, as mulheres estão disponíveis para acesso e uso, sendo machucadas, enforcadas, violentadas, utilizadas, ameaçadas, forçadas, enquanto são obrigadas a sorrir, como uma anuência à violência sofrida e como uma corroboração do prazer sentido na dor. Com este elemento corporal estampado no seu rosto, local de predileção do discurso social (BRETON, p. 85), a mulher demonstra consentir com o ato de violação e demonstra sentir prazer na dor. Elas sorriem, elas demonstram com seus sorrisos a sua anuência e o seu querer. As mulheres devem agir como se estivessem gostando disto (MACKINNON, 1996 p. 05).

Se na pornografia a mulher age como se estivesse experimentando prazer na dor, os homens, por outro lado, não expressam nada além do que ódio e, muito frequentemente, insultos (DINES, 2010, p. xxiv). Na pornografia, não há empatia entre os atores pornográficos. Os homens demonstram uma falta de excitação durante a relação sexual com a mulher. Não importa o tamanho da sua ereção, em seu rosto não está estampado nenhum sinal associado a excitação sexual. Para os homens, tudo gira em torno de sua ejaculação. Na pornografia, quando o homem goza, a relação sexual realmente acabou - não há nenhum sinal de intimidade com a mulher na qual ele ejaculou (DINES, 2010, p. xxiv) .

Ainda neste contexto, o prazer feminino somente existe para reforçar a virilidade masculina. Na pornografia, não há preocupação com o real prazer da mulher. De acordo com Catharine MacKinnon (1987, p. 58), a simulação do orgasmo é uma comprovação exemplar do poder masculino de fazer com que a interação dos sexos ocorra de acordo com a lógica androcêntrica: a mulher finge ter um orgasmo para que os homens tenham a prova de sua virilidade e dominação. Assim, nos materiais pornográficos, a mulher é um objeto disponibilizado para uso e acesso sexual irrestrito pelos homens: sua existência e todo seu valor se resumem a isso.

Somando-se ao fato das mulheres serem vistas como seres desumanizados, a pornografia também a condição de objetos, coisas, animais e/ou a partes restritas de seus corpos (DWORKIN, MACKINNON, 1989, p. 34). Na pornografia, a mulher é associada a objetos ou coisas para o uso masculino. Na pornografia, a mulher é personificada em forma de animais, como ocorre com as coelhinhas da Playboy, ou são identificadas como animais. Na pornografia, a mulher é isolada a uma parte de seu corpo, não se reconhecendo a pessoa mulher, mas apenas as partes femininas de seu corpo disponíveis para uso e posse. 
A pornografia, ao reduzir a mulher a condição de seu corpo, faz com que os interlocutores esqueçam que as representações do corpo são representações da pessoa, dissociando o corpo do ser que o encarna, conduzindo a sua objetificação, a sua redução a condição de coisa. David Le Breton, em seus estudos sobre corporeidade, já ressaltou a necessidade de se afastar o risco da fragmentação da identidade humana do homem, de um lado, e de seu corpo, de outro (LE BRETON, 2007, p. 26). Na pornografia, o risco e os danos da fragmentação do corpo da mulher e da sua identidade humana é ainda maior, pois acarreta na sua redução a um objeto inferior disponível para uso e acesso.

Para Gail Dines (2010, p. xvi), na pornografia, as mulheres são reduzidas aos seus orifícios ou partes de seus corpos; sua personalidade, sua alma, sua história, seu futuro, nada importa. Tudo gira em torno de onde penetrar alguém ou onde ser penetrado.

Neste contexto, outro ponto de crítica consiste no fato da pornografia construir arquétipos feminismos à luz da visão masculina. Na pornografia, ser feminina significa degradação, passividade, silêncio, anuência. As imagens e as palavras da pornografia traduzem a hierarquia social dos gêneros, trazendo sentimentos de inferioridade e de superioridade, em uma visão binária de sexualidade.

Além disto, a pornografia pode acarretar na padronização de comportamentos sexuais das mulheres, o que gera violência sexual em razão de limitar e anular o exercício livre da sexualidade feminina. A pornografia demonstra quais são as posições que devem ser realizadas durante o ato sexual, quais são as interlocuções sexuais que agradam aos homens, como deve ser a depilação feminina e como devem ser e se comportar seus corpos. Os corpos das mulheres que não se enquadram no arquétipo feminino da pornografia são dispensados ou intensamente menosprezados.

Outro grande ponto de grande crítica do feminismo anti-pornografia consiste nas correlações entre a pornografia com ilícitos penais, como o assédio sexual, o estupro, a pedofilia e o homicídio. Nos Estados-Unidos, a pornografia é permitida, mas estes ilícitos penais não. Todavia, para a corrente feminista anti-pornografia, a pornografia realiza e incentiva ilícitos penais.

Na pornografia, há gravações de cenas nas quais as mulheres são estupradas. Ocorre que enquanto as mulheres filmam serem estupradas, elas estão sendo efetivamente estupradas. Enquanto as mulheres filmam serem torturadas, elas estão sendo efetivamente torturadas 


\section{Raisa Duarte da Silva Ribeiro \& Marcela Siqueira Miguens}

(MACKINNON, 1996, p. 15). A pornografia causa estupro e tortura nas atrizes que representam ${ }^{13}$ cenas de estupro e tortura.

Além disto, a pornografia incentiva o estupro e a tortura, de uma forma bastante sutil. Na pornografia, a mulher aparece resistindo, diz que não quer, mas depois de rende ao final; na pornografia, o “não” significa “sim”; na pornografia, a mulher diz que não quer, mas seus corpos são utilizados da mesma forma e quando o são elas gostam (pois sorriem e pedem mais). Tudo isto causa a sensação nos seus consumidores de que as mulheres não dizem realmente não, causando a crença de que as mulheres não estão na verdade negando a relação sexual e que no final das contas elas vão gostar do que será feito a elas.

Na snuff pornography, mulheres e crianças são filmadas sendo assassinadas antes, durante ou após relações sexuais, sendo o assassinato sexualizado. Ocorre que o homicídio é um crime, mas a pornografia realiza a sua representação, despertando desejos em seus consumidores $^{14}$.

Na pornografia são realizadas cenas onde ocorrem abusos sexuais, cometidos pelos professores em face de suas alunas, cometidos pelos empregadores em face de mulheres que lhe são subordinadas. No entanto, o assédio, seja sexual ou não sexual, não é tutelado pelo ordenamento jurídico. Mas a pornografia cria condições para que os seus consumidores naturalizarem o assédio e o abuso cometido em face das mulheres.

A pedofilia é repudiada e criminalizada. Relações sexuais entre adultos e crianças ou adolescentes são proibidas. No entanto, a pornografia contrata mulheres adultas que aparentam ser cada vez mais novas para que sejam gravadas tendo relações sexuais com pessoas mais velhas (modalidade teen). A pornografia grava cenas nas quais a pedofilia aparenta estar envolvida, sugerindo e naturalizando este tipo de relação sexual.

Na pornografia, não são raros os casos em que as mulheres utilizam drogas e substâncias ilegais para aguentar as relações sexuais em que são submetidas. O ordenamento jurídico proíbe o tráfico e, em alguns Estados, até o uso próprio destas substâncias ilegais. A pornografia é um ramo envolvido e que sustenta este mercado ilegal de venda de drogas, mas a sua realização é livre.

\footnotetext{
${ }^{13}$ Na verdade, não se trata de uma representação porque representação não é realidade; a pornografia é realidade, os seus personagens vivenciam as cenas realizadas.

${ }^{14}$ A pornografia snuff foi uma das teses levantadas para justificar as mortes de mulheres que ocorreram no caso do Campo Algodoneiro, na Ciudad Juaréz, no México, que gerou a responsabilidade internacional do Estado Mexicano, no julgamento realizado em 2009 pela Corte Interamericana de Direitos Humanos. Para mais, vide: MIGUENS, RIBEIRO, 2018.
} 
A jurisprudência norte-americana, no entanto, refuta a causalidade da pornografia com ilícitos penais, sobre a argumentação de que a pornografia não perpetua a violência contra a mulher porque este dano depende de uma intermediação mental. A pornografia não causa a violência contra a mulher ${ }^{15}$, mas os atores criminais sim. Este posicionamento pode - e deve ser refutado de duas maneiras.

Em primeiro lugar, a jurisprudência não reconhece que a pornografia é capaz de gerar violência real contra as mulheres que realizam os filmes ou imagens pornográficas, ou seja, contra a mulher que realiza a pornografia. Como ressaltado, mulheres que realizam a pornografia são, muitas vezes, estupradas e torturadas, abusadas e forçadas a realizarem atos contra a sua vontade. Tudo isto caracteriza ilícitos penais causados pela realização da pornografia.

Em segundo lugar, os atores criminais são influenciados pela pornografia. A pornografia incentiva o cometimento de atos violentos ${ }^{16}$, através de uma intrusão mental inconsciente nos atores criminais. Por outro lado, os pornógrafos sabem exatamente o que estão fazendo, sabem exatamente quais são os discursos e as relações de poder envolvidas por de trás das imagens da pornografia.

As feministas radicais não querem retirar a responsabilidade dos agentes criminais pela prática de atos ilícitos em face das mulheres, mas querem demonstram que há uma causalidade entre o cometimento destes crimes e o consumo da pornografia. Não se ignora que os consumidores da pornografia possuem o livre arbítrio de pensar e de escolher se irão colocar em prática o que foi visto no âmbito pornográfico; mas se quer demonstrar que os discursos implícitos da pornografia são conscientemente formulados pelos seus produtores, com a intensão inegável de perpetuar a opressão contra a mulher.

Neste sentido, a pornografia causa intrusão mental inconsciente e manipulação física no mundo real. A pornografia constrói, reforça, define e corrobora a realidade existente. A pornografia reforça o papel da mulher na sociedade, destinando-lhe pela estrutura patriarcal, definindo o que ela é e o que pode ser feito com ela.

\footnotetext{
${ }^{15}$ De forma contrária, pode-se afirmar que a pornografia gera violência de gênero, seja em sua realização, seja em seu consumo. De forma isolada ou cumulativamente, os materiais pornográficos contemplam e incentivam a violência física, psicológica, moral, patrimonial e sexual contra a mulher. Para mais sobre a violência de gênero causada pela pornografia, vide: RIBEIRO, 2017, p. 124 e ss.

${ }^{16}$ Diana Russell constrói uma tese de múltipla causalidade entre o consumo constante de materiais pornográficos violentos e a realização de atos de violência contra a mulher, especificamente o estupro. RUSSELL, 1993.
} 
Conforme salientado por Catharine A. Mackinnon (1996, p. 15), o que a pornografia faz, ela faz no mundo real; a pornografia não possui efeitos apenas nas mentes de seus consumidores, mas ela produz realidades sociais relevantes. Para Andrea Dworkin, a pornografia é a lei para as mulheres (DWORKIN apud MACKINNON, 1996, p. 40).

Neste contexto, cabe salientar também que as feministas anti-pornografia veem a pornografia como uma arma da prostituição. A mulher é paga na pornografia para aparecer resistindo e depois se rende, mas isto não torna o sexo consensual. O que tornou o sexo consensual foi o dinheiro pago em retribuição ao trabalho prestado. O dinheiro é o meio coercitivo de força que realiza o consenso.

Neste contexto, com uma outra abordagem, Gail Dines ressalta que o dinheiro é o meio pelo qual se torna possível a realização de discursos na pornografia assimila o feminino com a completa falta de poder e o masculino com a detenção de todo o poder (2010, p. xxvii):

Por outro lado, faz-se mister ressaltar que a corrente feminista anti-pornografia não presume que toda a pornografia seja realizada em condições de abuso ou feita mediante coação. No entanto, sustenta-se que toda a pornografia é realizada mediante condições de desigualdade baseada no sexo (MACKINNON, 1996, p. 20). A indústria pornográfica explora, incentiva e mantem estas condições de desigualdade de gênero, sendo este um ponto central das críticas das feministas anti-pornografia.

No cenário jurídico estadunidense, as feministas anti-pornografia salientam que a pornografia vem sendo discutida, em âmbito constitucional, através da dicotomia liberdade de expressão dos pornógrafos e de seus consumidores versus censura das ideias sobre o sexo. No entanto, o âmbito da discussão sobre a pornografia não pode se inserir no contexto da Primeira Emenda do Bill Of Rights, mas deve perpassar e se concentrar no tema da igualdade de gênero.

De acordo com Catharine A. Mackinnon, a liberdade de expressão e a igualdade nunca foram contempladas no terreno constitucional estadunidense, pois ambas vem sendo interpretadas tradicionalmente mais negativa do que positivamente, ou seja, proibindo violações por parte do governo mais do que permitindo que este realize intervenções legais para mudanças sociais (MACKINNON, 1996, p. 73).

Ocorre que a análise da pornografia deve ser feita correlacionando a liberdade de expressão e a igualdade (RIBEIRO, 2017, p.211). As feministas radicais entendem que o igual acesso ao discurso deveria ser o ponto central da agenda da igualdade. É notório que certas pessoas possuem mais discursos do que outras. Conforme salientado por Catharine Mackinnon, 
quanto mais discurso para os dominantes, mais dominação; quanto menos discurso para os oprimidos, menos igualdade (1996, p. 72-73).

Ao se proteger o discurso dos pornógrafos, mais as mulheres se tornam oprimidas e silenciadas. Ao se proteger a pornografia, mais as vítimas de abusos possuem medo de falar em público. As vítimas de abusos não falam porque possuem medo de falar em público, reviverem novamente a situação de abuso vivida e serem desacreditadas. As vítimas de abuso quando relatam o abuso sofrido, utilizam a linguagem do assédio sexual, reproduzem a linguagem do abusadores, o que confronta com a linguagem do discurso público (MACKINNON, 1996, p. 64-68).

As mulheres ao relatarem o abuso sofrido utilizam as palavras do abusador e estas palavras são pornográficas. Ao relatar o abuso sofrido, as mulheres se tornam pornográficas e são silenciadas, pela própria lógica da pornografia, através da afirmação de que elas queriam ou pediram para que o ato de abuso ocorresse. Ou ainda, mediante a afirmação de que nada aconteceu, de que elas estão conscientemente mentindo ou falseando a verdade. O depoimento da vítima sobre o abuso sexual torna-a sexualizada; e, em razão da sua sexualização, ela não poderia ter sofrido abuso sexual, afinal ela existe para e pelo sexo (MACKINNON, 1996, p. 64-68).

Além do efeito silenciador causado, as vítimas, quando resolvem se manifestar, são desacreditadas, faltam-lhe credibilidade (FISS, 2005, p. 47). Afinal, quem iria escutar e escutar uma mulher que possui um pênis em sua boca? (MACKINNON, in ITZIN,1992, p. 483-484). Se este imaginário social para sempre perdurar, a credibilidade das mulheres nunca será efetivamente assegurada.

O efeito silenciador e a credibilidade não incidem apenas nas vítimas de abusos que queiram relatá-los, mas se dirige para todas as mulheres e, mais amplamente, para todas as minorias. Em razão da opressão sofrida e em razão do imaginário dentro do qual elas se inserem, as mulheres acreditam que nada do que elas falem possa acrescentar no debate. E quando são estimuladas a falar, falta-lhes a credibilidade.

Para Mackinnon (1996, p. 17), pornografia não é apenas palavras. Na realidade, fazer sexo é a antítese de pensar, é agir, é comportamento. Quem assiste a pornografia não está apenas pensando, mas está agindo, vivendo os prazeres do sexo. Com a pornografia, os seus consumidores se masturbam enquanto as mulheres são expostas, violadas, degradadas, 
mutiladas, torturadas. Ter um orgasmo não é uma ideia e este ato não pode ser confrontado, debatido.

As feministas anti-pornografia defendem que a restrição da pornografia é uma medida afirmativa a favor da igualdade de gênero. A liberdade de expressão dos pornógrafos é restringida para que se abra a possibilidade de ouvir novas vozes, para que se possibilite escutar as vozes dos oprimidos, tradicionalmente silenciados e desacreditados pelos discursos odiosos (MACKINNON, 1996, p. 68).

Ainda no contexto da liberdade de expressão, Gail Dines (2010, p. xvi) ressalta que os pornógrafos não estão interessados na criatividade ou no empoderamento sexual, mas estão, por outro lado, perseguindo o dinheiro. A indústria pornográfica é um dos mercados mais lucrativos da atualidade. Os pornógrafos não estão fazendo pornografia para exteriorizar suas ideias e pontos de vista sobre a sexualidade, mas sim para obterem ganhos lucrativos.

Ademais, outro argumento central pauta-se no fato de que os defensores da pornografia tendem a vê-la, no máximo, como uma difamação em face da mulher, sendo o preço que se paga pela garantia da liberdade de expressão, posição firmada e corroborada pela Suprema Corte norte-americana após o julgamento do leading case New York vs. Sullivan. No entanto, as feministas anti-pornografia entendem que a pornografia é mais do que difamação, sendo uma prática de discriminação em face da mulher, que são vistas como objetos sexuais que sentem prazer na violação, com a construção de um arquétipo feminino realizado sob o ponto de vista masculino.

A pornografia é vista pela corrente feminista em análise como uma perpetuação da opressão e manutenção da hierarquia de gênero, sendo a pornografia uma crítica dirigida ao feminismo. Para a segunda onda do feminismo, a pornografia pode ser entendida como um discurso de ódio em face das mulheres, discurso misógino, de raiva. A pornografia se insere dentro de uma complexa rede de poder, onde a relação sexual ilustra a quantidade de poder que os homens possuem sobre as mulheres.

Na pornografia, o homem possui todo o poder sobre a mulher: a relação sexual se desencadeia como o que ele quer, onde ele quer e como ele quer, pois ele controla o ritmo, a velocidade e a natureza dos atos (DINES, 2010, p. xxv).

Para ilustrar como a pornografia se insere dentro de uma cadeira de relações de poder, Gail Dines (2010, p. xxv) observa as cenas do porno gonzo onde há a relação sexual sendo realizada por mais de dois atores. De acordo com a autora, é impressionante como apenas poucas cenas possuem várias mulheres e apenas um homem, impressionante especialmente em 
razão de existir o ideário masculino de realizar sexo com mais de uma mulher ao mesmo tempo. A maior parte das cenas que possuem múltiplos atores são realizadas por vários homens e apenas uma única mulher.

Em razão da pornografia performatizar um discurso sobre dominação e degradação, cenas sexuais onde vários personagens sejam as mulheres podem traduzir perda de poder para os homens. Havendo mais de uma mulher na cena e apenas um homem pode ocorrer de uma das mulheres deterem o poder na condução da sexualidade, contrariando o discurso implícito inerente da pornografia.

Noutra toada, observa-se que a pornografia é viciante e, em razão do vício, os seus consumidores precisam consumi-la cada vez mais, com mais intensidade, para terem as mesmas sensações inicias. Poderia se correlacionar os vícios da pornografia com os vícios de um usuário de drogas, que precisa cada vez mais consumir mais para conseguir ter a mesma sensação que tinha no início.

Neste contexto, cabe mencionar as observações realizadas por Diana E. H. Russel (1993, p.11) de que a pornografia se tornou mais violenta no decorrer dos anos. Neste mesmo sentido, Gail Dines (2010, p. xvii) salienta que a pornografia que era considerada hard-core antigamente agora é considerada mainstream. Com a evolução da internet, com as novas formas de acesso à pornografia e com o vício dos consumidores, o mercado se tornou saturado e os consumidores começaram a se tornar entediados e desestimulados, o que fez com que os pornografos passassem a procurar novos caminhos que os tornassem diferentes, com produtos diferenciados. E a violência tornou-se o caminho mais perseguido (DINES, 2010, p. xvii).

Por fim, cabe frisar novamente que as críticas das feministas anti-pornografia não se destinam para o que a pornografia diz, mas se dirigem ao que a pornografia faz. As feministas anti-pornografia não estão preocupadas com o discurso sobre o sexo, com o falar sobre a sexualidade, mas com os efeitos negativos que a pornografia produz no mundo real, com o fato de que a pornografia machuca as mulheres e sua igualdade.

Ademais, cabe ressaltar os malefícios causados pela pornografia se confundem com os próprios malefícios causados pela sociedade patriarcal em que vivemos. Neste contexto, reconhecer os efeitos negativos da pornografia acarreta no reconhecimento dos efeitos maléficos da organização social em que vivemos (MACKINNON, 1989, p. 307).

\section{PORNOGRAFIA E SEXUALIDADE: REFLEXOS E CONSTRUÇÕES}


A pornografia é indissociável da sexualidade, embora o inverso não seja verdadeiro. Alguns autores, como Michel Foucault (1999), Pierre Bourdieu (2002) e, posteriormente, Michel Bozon (2004) observaram que a construção social possui um papel central na construção da sexualidade humana, de forma que se pode afirmar que a sexualidade não é apenas um dado da natureza, mas uma coordenação mental de uma atividade corporal apreendida através do contexto cultural inserido.

De acordo com Michel Foucault (1999), as sexualidades são construídas socialmente, dentro do contexto das relações de poder, saber e prazer. Para Foucault, os discursos sobre a sexualidade realizados pela Igreja, pela literatura e pelas novas técnicas racionais regulam o indivíduo.

Com base no construtivismo estruturalista, Pierre Bourdieu (2002, p. 04) argumentava que há estruturas objetivas no mundo social que podem coagir a ação dos indivíduos, sendo que estas estruturas são construídas pela própria sociedade, através de seus indivíduos que as incorporam, legitimam e reproduzem.

O feminismo de segunda onda comunga da ideia de que as estruturas sociais são compostas por grupos, sendo os indivíduos vistos como seres socialmente construídos. O gênero, a sexualidade, a raça são categorias socialmente construídas, envolvidas por sistemas de poder causadores de opressões e de privilégios.

De acordo com o autor, através do paradoxo da dóxa (2002, p. 04), as relações de dominação, privilégios e injustiças devem ser mantidas, aceitas e naturalizadas, sem qualquer transgressão ou subversão. O exemplo por excelência desta submissão paradoxal consiste na dominação masculina, resultante de uma violência simbólica, suave, insensível e invisível as suas próprias vítimas.

Pierre Bourdieu observou que a divisão social das coisas e das atividades ocorria através da oposição binária do masculino e do feminino, sendo os gêneros inscritos em relações de dois opostos e complementares, onde o masculino é sempre associado a características positivas e o feminino sempre associado a características negativas.

O ato sexual se insere no princípio do primado da masculinidade. A oposição entre os sexos se inscreve em uma série de oposições míticos-rituais, tais como os binômios alto/baixo, em cima/ em baixo, seco/úmido, quente/frio, ativo/passivo, móvel/imóvel (BOURDIEU, 2002, p. 19). A posição sexual considerada normal por diversas civilizações é aquela em que o homem 
fica por cima. De forma ilustrativa, Bourdieu (2002, p. 28) cita o Mito da Fonte, correlacionando a sexualidade da natureza e a sexualidade da cultura ${ }^{17}$.

Pela exposição realizada por Bourdieu, na sexualidade da natureza, havia o desvelamento recíproco dos desejos dos parceiros, que se reconheciam reciprocamente. Todavia, o homem descobriu que poderia alcançar o mesmo prazer, através de uma relação de dominação e de subordinação. A sexualidade passou a ser um reflexo da estrutura social hierárquica, sendo uma relação de dominação social, onde há o desejo masculino de posse e de dominação erotizada e há o reconhecimento feminino erotizado da dominação.

Nesta toada, a pornografia se insere e influencia a construção da sexualidade, de forma cultural, também chamada de sexualidade regulamentada. A sexualidade deixou de ser vista como um dado da natureza e passou a se inserir em um contexto de regulamentação. De acordo com Michel Bozon, os homens já não sabem mais se comportar-se sexualmente por instinto, necessitando de um aprendizado social para saber de que forma e maneira, quando e como agir (BOZON, pp. 13-14). Uma das formas do ser humano adquirir este aprendizado sexual é através da pornografia.

Neste sentido, a pornografia passa a ter o condão de ditar condutas sexuais, instituindo padrões comportamentais a serem seguidos por seus consumidores e telespectadores. Conforme salientado, a sexualidade da mulher explorada na pornografia nega-lhe o seu status humano. A sexualidade feminina é representada pela dor, pela depreciação, pela tortura sexual, pela humilhação e pelo uso, sendo erotizada a negação da humanidade da mulher (MACKINNON, 1989, p. 211).

Por outro lado, a pornografia explora a sexualidade masculina através da sua virilidade, do dever e poder de dominação masculina. A virilidade, conforme salientado por Pierre

\footnotetext{
17 "Foi na fonte (tala) que o primeiro homem encontrou a primeira mulher. Ela estava apanhando água quando o homem, arrogante, aproximou-se dela e pediu de beber. Mas ela havia chegado primeiro e ela também estava com sede. Descontente, o gomem a empurrou. Ela deu um passo em falso e caiu por terra. Então o homem viu as coxas da mulher, que eram diferentes das suas. E ficou paralisado de espanto. A mulher, mais astuciosa, ensinou-lhe muitas coisas: 'Deita-te, disse ela, e eu te direi para que servem teus órgãos'. Ele se estendeu por terra. Ela acariciou seu pênis, que se tornou duas vezes maior, e deitou-se sobre ele. O homem experimentou um prazer enorme. Ele passou a seguir a mulher por toda parte, para voltar a fazer o mesmo, pois ela sabia mais coisas que ele, como acender o fogo etc. Um dia, o homem disse à mulher: 'Eu quero te mostrar que eu também sei fazer coisas. Estendese, e eu me deitarei sobre ti'. A mulher se deitou por terra, e o homem se pôs sobre ela. E ele sentiu o mesmo prazer. E disse então à mulher: 'Na fonte, és tu (quem dominas); na casa, sou eu'. No espírito do homem são sempre estes últimos propósitos que contam, e desde então os homens gostam de montar sobre as mulheres. Foi assim que eles se tornaram os primeiros e são eles que devem governar” (BOURDIEU, 2002, p. 28).
} 


\section{Raisa Duarte da Silva Ribeiro \& Marcela Siqueira Miguens}

Bourdieu (2002, p. 62-64), leva ao investimento, às vezes até obrigatório, de jogos de violência masculina, e requerer o seu reconhecimento pelos seus pares.

Ainda neste contexto, cabe ressaltar que diversas pesquisas já foram realizadas no sentido de demonstrar como a pornografia influencia no comportamento sexual de seus consumidores. De acordo com algumas pesquisas realizadas e anunciadas no site da Organização Stop Porn Culture, cuja uma das fundadoras é a feminista Gail Dines, após o consumo de pornografia, os homens estão mais propícios a demonstrar menor empatia por vítimas de estupro, ter tendência crescente a um comportamento agressivo; acreditar que as mulheres que estão vestidas provocativamente estão pedindo para serem estupradas; demonstrar agressividade contra mulheres que flertam e, após, se recusam ao sexo; demonstrar crescente desinteresse sexual por suas namoradas e esposas; e demonstrar um maior interesse em coagir parceiros a atos sexuais indesejáveis ${ }^{18}$.

Ademais, outro ponto essencial neste contexto, salientado por Michel Bozon, referese ao fato da iniciação dos jovens na sexualidade e no tratamento diferenciado dado às meninas e aos meninos nesta etapa (2004, p.27). Neste momento, faz-se mister ressaltar que a pornografia vem, cada dia mais, auxiliando os jovens na sua entrada na vida sexual, criando significações da sexualidade e corroborando com a ordem andocêntrica do mundo na relação sexual. De acordo com pesquisas realizadas, nos Estados Unidos, crianças de apenas 11 anos já acessam regularmente a pornografia hardcore e o maior grupo de consumidores de pornografia na internet são meninos de 12 a 17 anos (STOP PORN CULTURE).

Desta forma, observa-se a sexualidade é um fenômeno que deve ser observado dentro do contexto social em que se está inserido, em razão de ser um dado social e culturalmente construído. A análise da pornografia é indissociável dos estudos da sexualidade da cultura, também chamada de sexualidade regulamentada, na medida em que se correlacionam mutuamente, perpetuando imaginários e construindo novas imagens.

\section{CONCLUSÃO}

A pornografia se insere em um cenário de grande discussão e de conflito entre filosóficos e estudiosos, inclusive entre correntes feministas diferentes. O presente trabalho possui o escopo fundamental de sintetizar os principais argumentos utilizados pelo movimento feminista anti-pornografia. Em razão das discussões sobre a pornografia realizadas por esta

\footnotetext{
${ }^{18}$ Dados extraídos do site: http://stoppornculture.org/about/about-the-issue/facts-and-figures-2/ Acesso em 25 jun. 2018.
} 
corrente serem mais intensas no cenário jurídico estadunidense, onde há grande liberdade para a produção dos materiais pornográficos, o presente trabalho se baseou em ativistas e estudiosas feministas que debruçam seus estudos e pesquisas nesse âmbito.

A Suprema Corte norte-americana firmou o seu entendimento no sentido de tutelar discursos dos pornógrafos, protegendo-os pela cláusula aberta da Primeira Emenda do Bill Of Rights. A única possibilidade de restrição da pornografia ocorre quando este envolver materiais obscenos, que são configurados quando preenchidos os parâmetros do teste de obscenidade fixados no leading case Miller v. California.

Para Catharine Mackinnon, a obscenidade se refere a moral, enquanto que a pornografia se refere a uma prática política, envolvida em relações de poder, com o objetivo de perpetuar a opressão contra a mulher. A Suprema Corte somente restringe a pornografia quando esta é obscena, ou seja, quando esta é imoral, sem pudor, envolver interesses lascivos ou representar de forma ofensiva ou inaceitável o sexo, e não possuir valores artístico, político, cultural e/ou literário. A delimitação do que seja um valor artístico do que seja um valor político ou cultural ou literário, no entanto, não é realizada. Além disto, a Suprema Corte parece que não se preocupa com os direitos das mulheres, na medida em que não enfrenta a questão da pornografia gerar e perpetuar a violência de gênero.

Tendo em mente que a obscenidade se refere à moralidade, observa-se que as críticas feministas contrárias a pornografia não se inserem em um campo de conservadorismo ou proteção da moral, diferente do que ocorre com a obscenidade, mas sim em razão dos efeitos negativos que a pornografia possui na promoção da igualdade de gênero.

O movimento feminista anti-pornografia sustenta que a indústria pornográfica trata as mulheres como objetos sexuais desumanizados, que não possuem auto-respeito e que sentem prazer na violação, bem como as reduzem à coisas, animais ou as restringem às partes sexuais dos seus corpos. Outro argumento contrário à pornografia refere-se a sua causalidade com a realização e com o incentivo de práticas penais ilícitas e diversas formas de violência de gênero.

Assim, essa corrente sustenta que o tratamento da pornografia não deve mais ser realizado no âmbito da liberdade de expressão, mas deve ser deslocado para a igualdade. A pornografia não causa no máximo a difamação das mulheres, como sustentado por seus defensores, mas gera discriminação de gênero. Na realidade, a discussão sobre a pornografia envolve a ponderação desses direitos fundamentais: de um lado, a liberdade de expressão dos 
pornógrafos e de seus consumidores; de outro, a igualdade das mulheres, que tem suas vozes silenciadas pela pornografia e seus corpos dilacerados por esses materiais.

Nesse contexto, observa-se que a pornografia produz realidades, remodelando a sexualidade feminina à luz de estereótipos de gênero construídos pela visão andocêntrica de mundo. Na pornografia, a sexualidade feminina é representada como submissa, passiva, degradada, sendo, em uma visão binária, o negativo associado a mulher.

Em razão da sexualidade ser socialmente construída, a pornografia auxilia na modelização dos comportamentos sexuais, ditando as condutas que vem ser realizadas pela mulher e pelo homem durante a relação sexual, limitando e restringindo a autonomia feminina.

Desta forma, as críticas realizadas pelo movimento feminista contrário à pornografia, por expor os reflexos dos materiais pornográficos na construção da sexualidade feminina - e também na própria construção da sexualidade masculina - e os seus impactos na sociedade devem ser vistas, sem dúvida, como uma denúncia da condição feminina.

\section{REFERÊNCIAS BIBLIOGRÁFICAS}

BOURDIEU, Pierre. A Dominação Masculina, $2^{\mathrm{a}}$ edição. Tradução Maria Helena Kuhner. Rio de Janeiro: Bertrand Brasil, 2002.

BOZON, Michel. Sociologia da Sexualidade. Tradução Maria de Lurdes Menezes. Rio de Janeiro: editora FGV, 2004.

BRETON, David Le. A Sociologia do Corpo, $2^{a}$ edição. Tradução de Sonia M. S. Fuhrmann. Petropólis, RJ: Vozes, 2007.

DWORKIN, Andrea. Pornography: men possessing women. New York, Penguin Group, 1981. ; MACKINNON, Catharine A. Pornography and Civil Rights - a New Day for Women’s Equality, Minneapolis, Organizing Against Pornography, 1989.

FERREIRA, Aurélio Buarque de Holanda. Novo Dicionário da Língua Portuguesa, Editora Nova Fronteira, 1986.

FISS, Owen M. A ironia da liberdade de expressão: estado, regulação e diversidade na esfera pública. Rio de Janeiro: Renovar, 2005

FOUCAULT, Michel. A História da Sexualidade I - A vontade de saber. Tradução de Maria Thereza da Costa Albuquerque e J. A Guilbon Albuquerue. 13ª Edição. Editora Graal, 1999. GAIL, Dines Pornland: how porn has hijacked our sexuality, Boston, Beacon Press, 2010. GRIFFIN, Susan. A mente chauvinista. In: ZVEIG, Connie e ABRAMS, Jerimiah. Ao encontro da sombra: o potencial oculto do lado escuro. Cultrix, 1991 
ITZIN, Catherine. (Org.) Pornography: women, violence and civil liberties. A radical view. Oxford: Oxford University Press, 1992.

MACKINNON, Catharine A. Feminism Unmodified, Discourses on Life and Law. Cambridge e Londres, Harvard University Press, 1987.

. Toward a feminist theory of state. Cambridge, Massachusetts: Harvard University Press, 1989.

. Only Words, Cambridge, Harvard University Press, 1996.

MIGUENS, Marcela Siqueira; RIBEIRO, Raisa Duarte da Silva. Direitos humanos das Mulheres e Violência de Gênero: a tutela do feminicídio pela Corte Interamericana de Direitos Humanos. CAED JUS, 2018.

OLIVERA, Adriana Vidal de. A Constituição e direitos das mulheres: uma análise dos estereótipos de gênero na Assembleia Constituinte e suas consequências no texto constitucional. Curitiba: Juruá, 2014.

RIBEIRO, Raisa Duarte da Silva. Discurso de ódio, violência de gênero e pornografia: entre a liberdade de expressão e a igualdade. Editora Multifoco, 2017.

; COSTA, Rodrigo de Souza. A restrição da pornografia obscena pela Suprema Corte Estadunidense: entre a liberdade de expressão e a proteção dos direitos das mulheres. CONPEDI, 2017.

RUSSEL, Diana E. H. Against Pornography: The Evidence of Harm, Bekerley, Russell Publications, 1993.

STOP PORN CULTURE ONG. Disponível em: http://www.pornhub.com/categories . Acesso em 10 jun. 2018.

Revista Brasileira de Direitos e Garantias Fundamentais | e-ISSN: 2526-0111 | Salvador | v. 4 | n. 1 | p. 148 - 168 | Jan/Jun. 